\title{
Clinical usefulness of testing for UDP glucuronosyltransferase 1 family, polypeptide A1 polymorphism prior to the inititation of irinotecan-based chemotherapy
}

\author{
TAISHI HARADA ${ }^{1}$, HARUHIRO SAITO ${ }^{1}$, FUMI KARINO ${ }^{1}$, TETSUYA ISAKA $^{1}$, SHUJI MURAKAMI ${ }^{1}$, \\ TETSURO KONDO $^{1}$, FUMIHIRO OSHITA ${ }^{1}$, YOHEI MIYAGI ${ }^{2}$ and KOUZO YAMADA ${ }^{1}$ \\ ${ }^{1}$ Department of Thoracic Oncology and ${ }^{2}$ Research Institute, Kanagawa Cancer Center, Yokohama, Kanagawa 241-0815, Japan
}

Received March 3, 2014; Accepted April 8, 2014

DOI: $10.3892 / \mathrm{mco} .2014 .308$

\begin{abstract}
An association between UDP glucuronosyltransferase 1 family, polypeptide A1 (UGT1A1) polymorphisms and irinotecan-induced neutropenia has been previously reported. In this study, we assessed the clinical usefulness of testing for UGT1A1 polymorphisms prior to the initiation of irinotecan-based chemotherapy, as this remains a controversial subject. A total of 136 lung cancer patients who were treated with a combination of nedaplatin and irinotecan as initial chemotherapy were assessed. Following exclusion of patients exhibiting low UGT1A1 enzyme activity, 70 patients were treated after UGT1A1 polymorphism testing (test group) and 66 patients were treated without UGT1A1 polymorphism testing (non-test group). We retrospectively analyzed and compared the adverse events between the test and the non-test groups and observed no reduction in hematological or non-hematological toxicities in the test group compared to that in the non-test group. Of the 9 patients with grade 4 or 5 non-hematological toxicity, 6 patients had febrile neutropenia (FN). All the patients with FN were aged $>70$ years. The incidence of adverse events was significantly higher among patients aged $>70$ years compared to that among younger patients. In conclusion, in patients treated with nedaplatin and irinotecan combination chemotherapy, UGT1A1 polymorphism testing prior to the initiation of chemotherapy did not reduce the incidence of adverse events. Therefore, UGT1A1 polymorphism testing alone may not be sufficient to predict the occurrence of severe adverse events and it may be more important to effectively manage adverse events, particularly in elderly patients.
\end{abstract}

Correspondence to: Dr Taishi Harada, Department of Thoracic Oncology, Kanagawa Cancer Center, Nakao 2-3-2, Asahi-ku, Yokohama, Kanagawa 241-0815, Japan

E-mail: tharada0118@gmail.com

Key words: lung cancer, UDP glucuronosyltransferase 1 family, polypeptide A1, irinotecan, nedaplatin, diarrhea, neutropenia

\section{Introduction}

Irinotecan is currently used as the standard chemotherapeutic agent for lung and colorectal cancer and its efficacy is dependent upon its activation by liver carboxyesterases to form the active metabolite $\mathrm{SN}-38$. SN-38 is eliminated predominantly by a glucuronidation reaction to $\mathrm{SN}-38 \mathrm{G}$. This glucuronidation reaction is mediated primarily by UDP glucuronosyltransferase 1 family, polypeptide A1 (UGT1A1) (1). Irinotecan, $\mathrm{SN}-38$ and $\mathrm{SN}-38 \mathrm{G}$ are all secreted into the bile by hepatocytes, with subsequent excretion into the small intestine (2). Dose-limiting toxicities of irinotecan are diarrhea and neutropenia and reduced enzyme activity and SN-38G formation is closely associated with severe toxicities (3). Genetic polymorphisms of UGT1A1 result in reduced enzyme activity, leading to decreased glucuronidation of SN-38 and, ultimately, in increased toxicity by irinotecan (3).

The association between UGT1A1*28 polymorphism and irinotecan-induced toxicities has been investigated (4). In East Asian populations, including the Japanese, the association between UGT1 $11^{*} 28$ and ${ }^{*} 6$ polymorphisms and irinotecan-induced toxicities was previously investigated $(3,5,6)$. In colorectal cancer, irinotecan-induced grade $3 / 4$ neutropenia occurs more frequently in patients with the homozygous UGT1A1"28 mutation ("28/"28), the homozygous UGT1A1* 6 mutation ( $" 6 / * 6)$ or the double heterozygous mutation ("1/"28 and " $\left.1 /{ }^{*} 6\right)$, compared to patients with the wildtype of UGT1A1"28 and " $6\left(" 1 /{ }^{*} 1\right.$ and $\left.{ }^{*} 1 /{ }^{*} 1\right)$, the heterozygous UGT1A1"28 mutation ("1/28) or the heterozygous UGT1A1"6 mutation $\left({ }^{*} 1 / /^{*} 6\right)(7-9)$. These findings were similar for Japanese patients $(9,10)$ and individuals with low enzyme activity constitute $\sim 10 \%$ of the Japanese population $(10,11)$.

The usefulness of UGT1A1 polymorphism testing prior to the initiation of chemotherapy in patients with lung cancer has not been clearly determined. Therefore, in this study, we aimed to assess the effect of excluding patients with low enzyme activity on the frequency and severity of irinotecan-induced toxicities.

\section{Materials and methods}

Study design. We retrospectively analyzed the treatment-related adverse events in patients receiving nedaplatin and irinotecan 
combination chemotherapy and compared the incidence of adverse events between two patient groups, according to whether the patients underwent UGT1A1 polymorphism testing prior to treatment. The patients in one group (test group) were those who underwent UGT1A1 polymorphism testing prior to treatment initiation and were found not to have low enzyme activity. Patients with low enzyme activity were excluded from the study. In the second group (non-test group) the patients proceeded to receive treatment without prior UGT1A1 polymorphism testing.

The adverse events were assessed according to the Common Terminology Criteria for Adverse Events, version 4.0 (http://evs.nci.nih.gov/ftp1/CTCAE/CTCAE_4.03_2010-06-14 _QuickReference_8.5x11.pdf). Hematological (leukopenia, neutropenia, thrombocytopenia and anemia) as well as non-hematological toxicities [diarrhea and febrile neutropenia $(\mathrm{FN})]$ were assessed.

Patients. Between November, 2007 and February, 2011, a total of 136 patients with lung cancer were assessed. The patients were all treated with a combination of nedaplatin and irinotecan as initial chemotherapy in the Kanagawa Cancer Center. Patients who received adjuvant chemotherapy were included in this study. No patient developed severe major
Table I. Results of UGT1A1 polymorphism testing.

\begin{tabular}{|c|c|c|c|}
\hline \multirow[b]{2}{*}{ UGT1A1*28 } & \multicolumn{3}{|c|}{ UGT1A1*6 } \\
\hline & $\begin{array}{c}{ }^{*} 1 /{ }^{*} 1 \\
\text { (wild-type) }\end{array}$ & $\begin{array}{c}{ }^{*} 1 /{ }^{*} 6 \\
\text { (heterozygous) }\end{array}$ & $\begin{array}{c}{ }^{*} 6 /{ }^{*} 6 \\
\text { (homozygous) }\end{array}$ \\
\hline $\begin{array}{l}{ }^{*} 1 /{ }^{*} 1 \\
\text { (wild-type) }\end{array}$ & 72 & 27 & 4 \\
\hline $\begin{array}{l}{ }^{*} 1 /{ }^{*} 28 \\
\text { (heterozygous) }\end{array}$ & 26 & 4 & - \\
\hline $\begin{array}{l}\text { *28/*28 } \\
\text { (homozygous) }\end{array}$ & 1 & - & - \\
\hline
\end{tabular}

Of the 134 lung cancer patients who were tested for UGT1A1 polymorphisms, 9 (6.7\%) exhibited low enzyme activity. UGT1A1, UDP glucuronosyltransferase 1 family, polypeptide A1 .

organ dysfunction. A total of 70 patients were finally included in the test group and 66 patients in the non-test group.

Treatment. All the patients were treated with nedaplatin and irinotecan combination chemotherapy. The regimen consisted

Table II. Patient characteristics.

\begin{tabular}{|c|c|c|c|}
\hline Characteristics & $\begin{array}{l}\text { Total, no. }(\%) \\
\quad(\mathrm{n}=136)\end{array}$ & $\begin{array}{l}\text { Test group }{ }^{\mathrm{a}} \text {, no. }(\%) \\
\qquad(\mathrm{n}=70)\end{array}$ & $\begin{array}{c}\text { Non-test group }^{\mathrm{b}} \text {, no. }(\%) \\
(\mathrm{n}=66)\end{array}$ \\
\hline $\begin{array}{l}\text { Age, years } \\
\text { median (range) }\end{array}$ & $66(37-83)$ & $68(37-80)$ & $64(39-83)$ \\
\hline \multicolumn{4}{|l|}{ Gender } \\
\hline Male & 91 (67) & $45(64)$ & $46 \quad(70)$ \\
\hline Female & $45 \quad(33)$ & $25 \quad(36)$ & $20 \quad(30)$ \\
\hline \multicolumn{4}{|l|}{ ECOG performance status } \\
\hline $0-1$ & $130(96)$ & 69 (99) & $61(92)$ \\
\hline 2 & $6(4)$ & 1 (1) & $5(8)$ \\
\hline \multicolumn{4}{|l|}{ Pathology } \\
\hline Adenocarcinoma & $68(50)$ & $35(50)$ & $33 \quad(50)$ \\
\hline Squamous cell carcinoma & $27(20)$ & $15(22)$ & $12(18)$ \\
\hline Small-cell carcinoma & $23(17)$ & $10(14)$ & $13(20)$ \\
\hline Others & 18 (13) & $10 \quad(14)$ & 8 (12) \\
\hline \multicolumn{4}{|l|}{ Clinical stage (UICC-7) } \\
\hline $\mathrm{I} / \mathrm{II}$ & $2(2)$ & $0(0)$ & $2(3)$ \\
\hline III & 33 (24) & $11(16)$ & $22 \quad(33)$ \\
\hline IV & $65(48)$ & $28(40)$ & $37(56)$ \\
\hline Reccurence & $6(4)$ & $4(6)$ & $2(3)$ \\
\hline Adjuvant & $30 \quad(22)$ & $27 \quad(38)$ & $3(5)$ \\
\hline \multicolumn{4}{|l|}{ UGT1A1 polymorphism } \\
\hline Wild-type & $44(32)$ & $44(63)$ & $0 \quad(0)$ \\
\hline Heterozygous & $26(19)$ & $26(37)$ & $0 \quad(0)$ \\
\hline Non-test & $66(49)$ & $0(0)$ & $66(100)$ \\
\hline
\end{tabular}

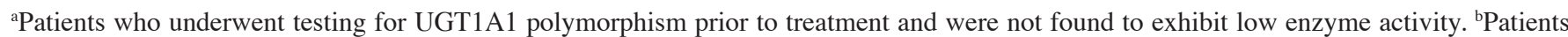
who did not undergo UGT1A1 polymorphism testing. ECOG, Eastern Cooperative Oncology Group; UICC, Union for International Cancer Control; UGT1A1, UDP glucuronosyltransferase 1 family, polypeptide A1. 
Table III. Comparison of adverse events between patient groups.

\begin{tabular}{|c|c|c|c|c|}
\hline Adverse events & $\begin{array}{l}\text { Total, no. }(\%) \\
\quad(n=136)\end{array}$ & $\begin{array}{l}\text { Test group, no. }(\%) \\
(\mathrm{n}=70)\end{array}$ & $\begin{array}{l}\text { Non-test group, no. }(\%) \\
\qquad(\mathrm{n}=66)\end{array}$ & P-value \\
\hline Grade $\geq 3$ & $37(22.1)$ & $19(27.1)$ & $18 \quad(27.2)$ & 0.99 \\
\hline Grade $\geq 4$ & $8(5.9)$ & $7(10.0)$ & $1 \quad(1.5)$ & 0.037 \\
\hline \multicolumn{5}{|l|}{ Neutropenia } \\
\hline Grade $\geq 3$ & 78 (57.3) & $38(54.3)$ & $40 \quad(60.6)$ & 0.46 \\
\hline Grade $\geq 4$ & $27(19.9)$ & $14(20.0)$ & 13 (19.7) & 0.96 \\
\hline \multicolumn{5}{|l|}{ Thrombocytopenia } \\
\hline Grade $\geq 3$ & 28 (20.6) & $14(20.0)$ & 14 (21.2) & 0.83 \\
\hline Grade $\geq 4$ & $11(8.1)$ & $8(11.4)$ & $3(4.5)$ & 0.14 \\
\hline \multicolumn{5}{|l|}{ Anemia } \\
\hline Grade $\geq 3$ & $20(14.7)$ & $10(14.3)$ & $10(15.1)$ & 0.88 \\
\hline Grade $\geq 4$ & $1(0.7)$ & $1(1.4)$ & $0 \quad(0.0)$ & 0.51 \\
\hline \multicolumn{5}{|l|}{ Hematological toxicities } \\
\hline Grade $\geq 3$ & $83(61.0)$ & $40 \quad(57.1)$ & $43(65.2)$ & 0.34 \\
\hline Grade $\geq 4$ & 28 (20.6) & $15(21.4)$ & 13 (19.6) & 0.80 \\
\hline \multicolumn{5}{|l|}{ Febrile neutropenia $^{\mathrm{a}}$} \\
\hline Grade $\geq 3$ & $12(8.8)$ & $5(7.1)$ & 7 (10.6) & 0.48 \\
\hline Grade $\geq 4$ & $6(4.4)$ & $4(5.7)$ & $2(3.0)$ & 0.37 \\
\hline \multicolumn{5}{|l|}{ Diarrhea } \\
\hline Grade $\geq 3$ & $9(6.6)$ & $6(8.6)$ & $3(4.5)$ & 0.28 \\
\hline Grade $\geq 4$ & $3(2.2)$ & $2(2.9)$ & $1 \quad(1.5)$ & 0.52 \\
\hline \multicolumn{5}{|l|}{ Non-hematological toxicities } \\
\hline Grade $\geq 3$ & 38 (27.9) & $24(34.3)$ & $14(21.2)$ & 0.089 \\
\hline Grade $\geq 4$ & $9(6.6)$ & $7(10.0)$ & $2(3.0)$ & 0.097 \\
\hline Treatment-related mortality & $4(2.9)$ & $3(4.3)$ & $1 \quad(1.5)$ & 0.33 \\
\hline
\end{tabular}

The comparisons between the two groups were performed with the Chi-square test. Adverse events were evaluated with Common Terminology Criteria for Adverse Events, version 4.0. ${ }^{\mathrm{a} F e b r i l e ~ n e u t r o p e n i a ~ w a s ~ t r e a t e d ~ a s ~ a ~ n o n-h e m a t o l o g i c a l ~ t o x i c i t y . ~}$

of four cycles of $50 \mathrm{mg} / \mathrm{m}^{2}$ nedaplatin on days 1 and 8 and $50 \mathrm{mg} / \mathrm{m}^{2}$ irinotecan on days 1 and 8 , every 4 weeks $(12,13)$. Cisplatin and irinotecan combination chemotherapy is known to be effective for small-cell and non-small-cell lung cancer $(14,15)$. In Japan, cisplatin and irinotecan combination chemotherapy is one of the standard chemotherapy regimens used for the treatment of lung cancer. Nedaplatin is an analogue of cisplatin, with relatively low neurotoxicity and nephrotoxicity and high in vivo bioavailability. Three-dimensional analysis models have demonstrated a remarkable synergistic interaction of platinum administration concurrently with irinotecan; this synergistic interaction has also been observed with the combination of nedaplatin and irinotecan (16).

Testing for UGT1A1 polymorphism. UGT1A1 polymorphisms were identified with a modified loop-hybrid mobility shift assay. When loop-hybrids using a Cy5-tagged probe for the *28 and *6 locus were combined and used for mobility shift assay, simultaneous typing of the ${ }^{*} 28$ and ${ }^{*} 6$ variants was achieved in a single lane (17).
Statistical analysis. Differences between groups were assessed with the t-test and the Chi-square test. $\mathrm{P}<0.05$ was considered to indicate statistically significant differences.

\section{Results}

UGT1A1 polymorphism. We tested for UGT1A1 polymorphisms in 134 lung cancer patients in the Kanagawa Cancer Center and identified 9 patients $(6.7 \%)$ with low enzyme activity. The results of the UGT1A1 polymorphism testing are presented in Table I.

Following exclusion of the 9 patients exhibiting low enzyme activity, 70 patients were treated with a combination of nedaplatin and irinotecan as initial chemotherapy after UGT1A1 polymorphism testing. The remaining 64 patients were administered a different therapy or were not treated. A further 66 patients were also treated with a combination of nedaplatin and irinotecan as initial chemotherapy, but without UGT1A1 polymorphism testing prior to treatment initiation.

Patient characteristics. The characteristics of the 136 study patients (test group, $n=70$; non-test group, $n=66$ ) who were 
Table IV. Characteristics of 9 patients with severe non-hematological toxicities.

Patient characteristics

Grade of adverse events ${ }^{\mathrm{a}}$

\begin{tabular}{|c|c|c|c|c|c|c|c|c|}
\hline $\begin{array}{l}\text { Age } \\
\text { (years) }\end{array}$ & Gender & UGT1A1 & PS & Pathology & cStage & $\mathrm{FN}$ & Diarrhea & $\begin{array}{l}\text { Other severe } \\
\text { NH toxicities }\end{array}$ \\
\hline 73 & Female & Non-test & 1 & $\mathrm{SCC}$ & IV & 4 & - & - \\
\hline 83 & Male & Non-test & 1 & NSCLC & IIIB & 5 & 5 & - \\
\hline 56 & Male & Wild-type & 1 & Adenocarcinoma & IV & - & - & $5^{\mathrm{c}}$ \\
\hline 69 & Male & Wild-type & 1 & $\mathrm{SCC}$ & IV & - & - & $5^{\mathrm{c}}$ \\
\hline 72 & Male & Wild-type & 1 & Adenocarcinoma & IV & 5 & 5 & - \\
\hline 73 & Male & Wild-type & 1 & $\mathrm{SCC}$ & IV & 4 & 3 & - \\
\hline 77 & Male & *28 heterozygous & 0 & Adenocarcinoma & IV & 4 & 4 & - \\
\hline 67 & Male & *6 heterozygous & 1 & LCNEC & IV & - & - & $4^{\mathrm{d}}$ \\
\hline 78 & Male & *6 heterozygous & 1 & SCLC & IV & 4 & 3 & - \\
\hline
\end{tabular}

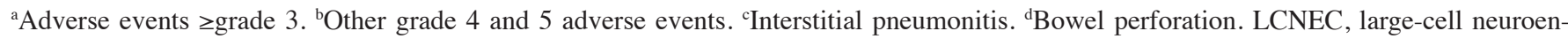
docrine carcinoma; FN, febrile neutropenia; NH, non-hematological; UGT1A1, UDP glucuronosyltransferase 1 family, polypeptide A1; PS, performance status; SCC, squamous cell carcinoma; SCLC, small-cell lung cancer; NSCLC, non-small-cell lung cancer.

Table V. Characteristics of the elderly and non-elderly patients.

\begin{tabular}{|c|c|c|c|}
\hline Characteristics & $\begin{array}{l}\text { Total, no. }(\%) \\
\quad(\mathrm{n}=136)\end{array}$ & $\begin{array}{l}\text { Elderly, no. }(\%) \\
\qquad(\mathrm{n}=46)\end{array}$ & $\begin{array}{l}\text { Non-elderly, no. }(\%) \\
\qquad(\mathrm{n}=90)\end{array}$ \\
\hline $\begin{array}{l}\text { Age, years } \\
\text { median (range) }\end{array}$ & $66(37-83)$ & $74(70-83)$ & $63(37-69)$ \\
\hline \multicolumn{4}{|l|}{ Gender } \\
\hline Male & $91 \quad(67)$ & $32(70)$ & $59(66)$ \\
\hline Female & $45 \quad(33)$ & $14(30)$ & 31 (34) \\
\hline \multicolumn{4}{|l|}{ ECOG performance status } \\
\hline $0-1$ & $130(96)$ & $44(96)$ & $86(96)$ \\
\hline 2 & $6(4)$ & $2(4)$ & $4(4)$ \\
\hline \multicolumn{4}{|l|}{ Pathology } \\
\hline Adenocarcinoma & $68(50)$ & $26(57)$ & 42 (47) \\
\hline Squamous cell carcinoma & $27(20)$ & $8(17)$ & $19(21)$ \\
\hline Small-cell carcinoma & $23(17)$ & $7(15)$ & $16(18)$ \\
\hline Others & $18(13)$ & $5(11)$ & $13(14)$ \\
\hline \multicolumn{4}{|l|}{ Clinical stage (UICC-7) } \\
\hline $\mathrm{I} / \mathrm{II}$ & $2(2)$ & $2(4)$ & $0(0)$ \\
\hline III & 33 (24) & $12(26)$ & $39(44)$ \\
\hline IV & $65(48)$ & $19(41)$ & $28(31)$ \\
\hline Recurrence & $6(4)$ & $3(7)$ & $3(3)$ \\
\hline Adjuvant & 30 (22) & $10(22)$ & $20(22)$ \\
\hline \multicolumn{4}{|l|}{ UGT1A1 polymorphism } \\
\hline Wild-type & $44 \quad(32)$ & $20(43)$ & $24(27)$ \\
\hline Heterozygous & 26 (19) & $10(22)$ & $16(18)$ \\
\hline Non-test & 66 (49) & $16(35)$ & $50(55)$ \\
\hline
\end{tabular}

ECOG, Eastern Cooperative Oncology Group; UICC, Union for International Cancer Control; UGT1A1, UDP glucuronosyltransferase 1 family, polypeptide A1.

treated with a combination of nedaplatin and irinotecan as initial chemotherapy are summarized in Table II. The median age of the total study group was 66 years (range, 37-83 years).
The median age of the test group was higher compared to that of the non-test group, but there was no difference in age distribution. The tumors were classified as 68 adenocarcinomas, 
Table VI. Comparison of adverse events between elderly ( $\geq 70$ years) and non-elderly ( $<70$ years) patients.

\begin{tabular}{|c|c|c|c|c|}
\hline Adverse events & $\begin{array}{l}\text { Total, no. }(\%) \\
\quad(\mathrm{n}=136)\end{array}$ & $\begin{array}{l}\text { Elderly, no. }(\%) \\
\qquad(\mathrm{n}=46)\end{array}$ & $\begin{array}{l}\text { Non-elderly, no. }(\%) \\
\qquad(\mathrm{n}=90)\end{array}$ & P-value \\
\hline \multicolumn{5}{|l|}{ Leukopenia } \\
\hline Grade $\geq 3$ & $37 \quad(22.1)$ & 15 (32.6) & $22(24.4)$ & 0.31 \\
\hline Grade $\geq 4$ & $8 \quad(5.9)$ & 8 (17.4) & $0 \quad(0.0)$ & 0.001 \\
\hline \multicolumn{5}{|l|}{ Neutropenia } \\
\hline Grade $\geq 3$ & $78 \quad(57.3)$ & $31 \quad(67.4)$ & $47 \quad(52.2)$ & 0.091 \\
\hline Grade $\geq 4$ & $27(19.9)$ & $14 \quad(30.4)$ & $13 \quad(14.4)$ & 0.027 \\
\hline \multicolumn{5}{|l|}{ Thrombocytopenia } \\
\hline Grade $\geq 3$ & $28 \quad(20.6)$ & $12(26.1)$ & $16 \quad(17.8)$ & 0.26 \\
\hline Grade $\geq 4$ & $11(8.1)$ & 7 (15.2) & $4 \quad(4.4)$ & 0.035 \\
\hline \multicolumn{5}{|l|}{ Anemia } \\
\hline Grade $\geq 3$ & $20(14.7)$ & $8 \quad(17.4)$ & 12 & 0.53 \\
\hline Grade $\geq 4$ & $1(0.7)$ & $1 \quad(2.2)$ & $0 \quad(0.0)$ & 0.34 \\
\hline \multicolumn{5}{|l|}{ Hematological toxicities } \\
\hline Grade $\geq 3$ & $83 \quad(61.0)$ & $33 \quad(71.7)$ & $50 \quad(55.6)$ & 0.057 \\
\hline Grade $\geq 4$ & $28 \quad(20.6)$ & $15 \quad(32.6)$ & 13 (14.4) & 0.013 \\
\hline \multicolumn{5}{|l|}{ Febrile neutropenia } \\
\hline Grade $\geq 3$ & $12(8.8)$ & $8 \quad(17.4)$ & $4 \quad(4.4)$ & 0.016 \\
\hline Grade $\geq 4$ & $6 \quad(4.4)$ & $6 \quad(13.0)$ & $\begin{array}{ll}0 & (0.0)\end{array}$ & 0.001 \\
\hline \multicolumn{5}{|l|}{ Diarrhea } \\
\hline Grade $\geq 3$ & $9(6.6)$ & $6 \quad(13.0)$ & $3(3.3)$ & 0.040 \\
\hline Grade $\geq 4$ & $3(2.2)$ & $3(6.5)$ & $\begin{array}{ll}0 & (0.0)\end{array}$ & 0.037 \\
\hline \multicolumn{5}{|l|}{ Non-hematological toxicities } \\
\hline Grade $\geq 3$ & 38 (27.9) & $18 \quad(39.1)$ & $20 \quad(22.2)$ & 0.037 \\
\hline Grade $\geq 4$ & $9(6.6)$ & $6(13.0)$ & $3(3.3)$ & 0.040 \\
\hline Treatment-related mortality & $4 \quad(2.9)$ & $2(4.3)$ & $2(2.2)$ & 0.42 \\
\hline
\end{tabular}

27 squamous cell carcinomas and 23 small-cell carcinomas. A total of 98 patients had clinical stage III-IV disease, according to the criteria of the Union for International Cancer Control, version 7 (18). After surgery, 30 patients received adjuvant chemotherapy. The median number of treatment cycles was 3 (range, 1-4 cycles). Adjuvant chemotherapy was administered to 27 patients $(38 \%)$ in the test group and to only 3 patients $(5 \%)$ in the non-test group.

Toxicities. The adverse events are listed in Table III. Of the total study population, grade 4 neutropenia occurred in 27 patients $(19.9 \%), \geq$ grade 3 diarrhea in 9 patients $(6.6 \%)$ and $\geq$ grade $3 \mathrm{FN}$ in 12 patients $(8.8 \%)$. There were 4 treatment-related deaths (2.9\%): 2 patients succumbed to FN and diarrhea and 2 patients succumbed to interstitial pneumonitis (IP). In the test group, grade 4 neutropenia occurred in 14 patients $(20.0 \%), \geq$ grade 3 diarrhea in 6 patients $(8.6 \%)$ and $\geq$ grade $3 \mathrm{FN}$ in 5 patients $(7.1 \%)$. In the non-test group, grade 4 neutropenia occurred in 13 patients $(19.7 \%), \geq$ grade 3 diarrhea in 3 patients $(4.5 \%)$ and $\geq$ grade $3 \mathrm{FN}$ in 7 patients $(10.6 \%)$. There was no significant reduction in any of the adverse effects in the test group compared to the non-test group.
We evaluated grade 4 or 5 non-hematological toxicities separately, since, when severe, these toxicities are considered to be the most important in the clinical field. Of the total study population, grade 4 or 5 non-hematological toxicities occurred in 9 patients $(6.6 \%)$, with 6 patients developing FN and 3 patients developing IP or bowel perforation (Table IV). All 6 patients with FN were elderly (aged $\geq 70$ years) and 5 of these patients developed FN concurrently with $\geq$ grade 3 diarrhea.

Comparison of adverse events between elderly and non-elderly patients. We hypothesized that the incidence of severe toxicities may be higher among elderly patients and we compared the incidence of adverse events between the 46 elderly ( $\geq 70$ years) and the 90 non-elderly ( $<70$ years) patients (Table V). It should be noted that more patients were tested for UGT1A1 polymorphisms in the non-elderly group. The adverse events are listed in Table VI. In the elderly group, grade 4 neutropenia occurred in 14 patients $(30.4 \%)$, $\geq$ grade 3 diarrhea in 6 patients $(13.0 \%)$ and $\geq$ grade $3 \mathrm{FN}$ in 8 patients $(17.4 \%)$. In the non-elderly group, grade 4 neutropenia occurred in 13 patients $(14.4 \%)$, $\geq$ grade 3 diarrhea in 3 patients $(3.3 \%)$ and $\geq$ grade $3 \mathrm{FN}$ in 4 patients $(4.4 \%)$. These adverse events were significantly more frequent among elderly rather than among non-elderly patients. 
Similarly, other hematological and non-hematological toxicities were more frequent among elderly patients. Therefore, elderly patients exhibited a higher risk for toxicities associated with nedaplatin and irinotecan combination chemotherapy.

When the adverse events were compared by other background factors, such as gender, PS, adjuvant chemotherapy and UGT1A1 polymorphisms, no significant differences in incidence were observed between groups.

\section{Discussion}

The association between UGT1A1 polymorphism and the risk of irinotecan-induced toxicity is dose-dependent. In 2005, the US Food and Drug Administration recommended testing for UGT1A1*28 polymorphism for dose regulation of irinotecan. As regards colorectal cancer, studies on the optimal dose of irinotecan for the treatment of patients with low enzyme activity have been conducted $(19,20)$. However, the optimal dose of irinotecan for lung cancer patients with low enzyme activity has not been determined and remains a subject of controversy.

In the present study, we observed no reduction in the incidence of adverse events among patients in the test group compared to those in the non-test group, which may be explained as follows: First, since the number of patients exhibiting low enzyme activity was low, the exclusion of such patients exerted a limited effect on the overall incidence of adverse results. In our UGT1A1 polymorphism testing of 134 patients, only 9 patients $(6.7 \%)$ exhibited low enzyme activity. In the Japanese population, the frequency of individuals with low enzyme activity was reported to be $\sim 10 \%$ (11).

Second, the dose of irinotecan in our study was low, which may explain the lack of significant between-group differences in adverse events. A previous meta-analysis demonstrated that the risks of adverse events with low-dose irinotecan $\left(<150 \mathrm{mg} / \mathrm{m}^{2}\right)$ were similar between patients with UGT1A1 ( $1 / /^{*} 1$ or $\left.{ }^{*} 1 / /^{*} 28\right)$ (21). However, a later meta-analysis reported that the risk of adverse events was higher, even at low doses of irinotecan $\left(<150 \mathrm{mg} / \mathrm{m}^{2}\right)$, in patients with UGT1A1 $28\left({ }^{*} 28 /{ }^{*} 28\right)$ compared to those with UGT1A1*28 $\left({ }^{*} 1 /^{*} 1\right.$ or $\left.{ }^{*} 1 /^{*} 28\right)(22)$. In the present study, the regimen consisted of four cycles of $50 \mathrm{mg} / \mathrm{m}^{2}$ nedaplatin on days 1 and 8 and $50 \mathrm{mg} / \mathrm{m}^{2}$ irinotecan on days 1 and 8 , every 4 weeks.

The higher ratio of adverse events in the test group may be attributed to the number of elderly patients in that group. Although there was no between-group difference in age distribution, there were $30(42 \%)$ elderly patients in the test group, but only $16(24 \%)$ in the non-test group. Therefore, elderly patients may be at a higher risk of developing nedaplatin and irinotecan combination chemotherapy-related toxicities compared to non-elderly patients.

Several of the patients with severe toxicities synchronously developed FN and diarrhea. All 9 patients with $\geq$ grade 3 diarrhea had fever. Among the 14 patients with grade 2 diarrhea, 9 patients had fever. Among the 113 patients with grade 0 or 1 diarrhea, 14 patients had fever. Patients with $\geq$ grade 2 diarrhea had fever more frequently compared to patients with grade 0 or 1 diarrhea $(\mathrm{P}<0.001)$. Diarrhea may lead to dehydration, which is a risk of severe $\mathrm{FN}$, as is an age of $\geq 60$ years $(23,24)$. Patients with diarrhea are also considered to be at high risk of infection and severe FN.
A meta-analysis demonstrated that the risk of irinotecan-induced diarrhea in patients with UGT1A1 ( $28 /^{*} 28$ or $\left.{ }^{*} 1 /{ }^{*} 28\right)$ was higher compared to that in patients with UGT1A1 $\left({ }^{*} 1 /^{*} 1\right)$ at medium and high doses (25). However, the association between UGT1A1 polymorphism and irinotecan-induced diarrhea has been controversial. In addition to UGT1A1 polymorphisms, an association between irinotecan-induced gastrointestinal toxicity and polymorphisms of the ABCC5, ABCG1 and SLCO1B1 genes has also been reported (26).

The dose-limiting toxicities of irinotecan are diarrhea and neutropenia. Patients with diarrhea are also at a high risk of infection. Therefore, it is important to effectively manage irinotecan-induced diarrhea and neutropenia. High-dose loperamide has been shown to be efficient for managing delayed diarrhea $(27,28)$. Furthermore, the efficacy of oral alkalization for the prevention of irinotecan-induced diarrhea has been reported (29).

Patients with low enzyme activity are at high risk of severe neutropenia. However, with UGT1A1 polymorphism testing alone, it may be difficult to predict the onset of severe adverse events. Regarding the safety and efficacy of irinotecan administration, it is more important to manage adverse events effectively in the clinical field. For elderly patients, in particular, their management while administering irinotecan and nedaplatin combination chemotherapy should be handled with caution. Further investigation on the prevention of irinotecan-induced diarrhea is required.

\section{References}

1. Iyer L, King CD, Whitington PF, Green MD, Roy SK, Tephly TR, Coffman BL and Ratain MJ: Genetic predisposition to the metabolism of irinotecan (CPT-11). Role of uridine diphosphate glucuronosyltransferase isoform 1A1 in the glucuronidation of its active metabolite (SN-38) in human liver microsomes. J Clin Invest 101: 847-854,1998.

2. Lokiec F, Canal P, Gay C, Chatelut E, Armand JP, Roché H, Bugat R, Gonçalvès $\mathrm{E}$ and Mathieu-Boué $\mathrm{A}$ : Pharmacokinetics of irinotecan and its metabolites in human blood, bile, and urine. Cancer Chemother Pharmacol 36: 79-82, 1995.

3. Minami H, Sai K, Saeki M, Saito Y, Ozawa S, Suzuki K, Kaniwa N, Sawada J, Hamaguchi T, Yamamoto N, Shirao K, Yamada Y, Ohmatsu H, Kubota K, Yoshida T, Ohtsu A and Saijo N: Irinotecan pharmacokinetics/pharmacodynamics and UGT1A genetic polymorphisms in Japanese: roles of UGT1A1"6 and *28. Parmacogenet Genomics 17: 497-504, 2007.

4. Iyer L, Das S, Janisch L, Wen M, Ramírez J, Karrison T, Fleming GF, Vokes EE, Schilsky RL and Ratain MJ: UGT1A1*28 polymorphism as a determinant of irinotecan disposition and toxicity. Pharmacogenomics J 2: 43-47, 2002.

5. Sai K, Saeki M, Saito Y, Ozawa S, Katori N, Jinno H, Hasegawa R, Kaniwa N, Sawada J, Komamura K, Ueno K, Kamakura S, Kitakaze M, Kitamura Y, Kamatani N, Minami H, Ohtsu A, Shirao K, Yoshida T and Saijo N: UGT1A1 haplotypes associated with reduced glucuronidation and increased serum bilirubin in irinotecan-administered Japanese patients with cancer. Clin Pharmacol Ther 75: 501-515, 2004.

6. Han JY, Lim HS, Shin ES, Yoo YK, Park YH, Lee JE, Jang IJ, Lee DH and Lee JS: Comprehensive analysis of UGT1A1 polymorphisms predictive for pharmacokinetics and treatment outcome in patients with non-small-cell lung cancer treated with irinotecan and cisplatin. J Clin Oncol 24: 2237-2244, 2006.

7. Glimelius B, Garmo H, Berglund A, Fredriksson LA, Berglund M, Kohnke H, Byström P, Sørbye H and Wadelius M: Prediction of irinotecan and 5-fluorouracil toxicity and response in patients with advanced colorectal cancer. Pharmacogenomics J 11: 61-71, 2011. 
8. Shulman K, Cohen I, Barnett-Griness O, Kuten A, Gruber SB Lejbkowicz F and Rennert G: Clinical implications of UGT1A $1 * 28$ genotype testing in colorectal cancer patients. Cancer 117: 3156-3162, 2011

9. Okuyama Y, Hazama S, Nozawa H, Kobayashi M, Takahashi K, Fujikawa K, Kato T, Nagata N, Kimura H, Oba K, Sakamoto J and Mishima H: Prospective phase II study of FOLFIRI for mCRC in Japan, including the analysis of UGT1A $1^{*} 28 /{ }^{*} 6$ polymorphisms. Jpn J Clin Oncol 41: 477-482, 2011.

10. Yamamoto N, Takahashi T, Kunikane H, Masuda N, Eguchi K, Shibuya M, Takeda Y, Isobe H, Ogura T, Yokoyama A and Watanabe K: Phase I/II pharmacokinetic and pharmacogenomic study of UGT1A1 polymorphism in elderly patients with advanced non-small cell lung cancer treated with irinotecan Clinical Pharmacol Ther 85: 149-154, 2009.

11. Akiyama Y, Fujita K, Nagashima F, Yamamoto W, Endo H, Sunakawa Y, Yamashita K, Ishida H, Mizuno K, Araki K, Ichikawa W, Miya T, Narabayashi M, Kawara K, Sugiyama M, Hirose T, Ando Y and Sasaki Y: Genetic testing for UGT1A1*28 and ${ }^{*} 6$ in Japanese patients who receive irinotecan chemotherapy. Ann Oncol 19: 2089-2094, 2008.

12. Oshita F, Saito H and Yamada K: Feasible combination chemotherapy with nedaplatin and irinotecan for patients with non-small cell lung cancer and multiple risk factors. J Exp Ther Oncol 6: 251-256, 2007.

13. Oshita F, Yamada K, Kato Y, Ikehara M, Noda K, Tanaka G, Nomura I, Suzuki R and Saito H: Phase I/II study of escalating doses of nedaplatin in combination with irinotecan for advanced non-small-cell lung cancer. Cancer Chemother Pharmacol 52: 73-78, 2003.

14. Noda K, Nishiwaki Y, Kawahara M, Negoro S, Sugiura T, Yokoyama A, Fukuoka M, Mori K, Watanabe K, Tamura T, Yamamoto S and Saijo N; Japan Clinical Oncology Group: Irinotecan plus cisplatin compared with etoposide plus cisplatin for extensive small-cell lung cancer. N Engl J Med 346: 85-91, 2002.

15. Ohe Y, Ohashi Y, Kubota K, Tamura T, Nakagawa K, Negoro S, Nishiwaki Y, Saijo N, Ariyoshi Y and Fukuoka M: Randomized phase III study of cisplatin plus irinotecan versus carboplatin plus paclitaxel, cisplatin plus gemcitabine, and cisplatin plus vinorelbine for advanced non-small-cell lung cancer: Four-Arm Cooperative Study in Japan. Ann Oncol 18: 317-323, 2007.

16. Kanzawa F, Koizumi F, Koh Y, Nakamura T, Tatsumi Y, Fukumoto H, Saijo N, Yoshioka T and Nishio K: In vitro synergistic interactions between the cisplatin analogue nedaplatin and the DNA topoisomerase I inhibitor irinotecan and the mechanism of this interaction. Clin Cancer Res 7: 202-209, 2001.

17. Matsukuma S, Saito H, Yamada K, Okamoto N, Ishikawa T, Yoshihara M, Koizume S, Sakuma Y and Miyagi Y: Simple and precise detection of UGT1A1 polymorphisms with a modified loop-hybrid mobility shift assay using Cy5-labeled loop probes. Clin Chim Acta 412: 1668-1672, 2011.

18. Sobin LH, Gospodarowicz MK, Wittekind C (eds): TNM Classification of Malignant Tumors. 7th edition. Wiley-Blackwell, NY, 2009.
19. Satoh T, Ura T, Yamada Y, Yamazaki K, Tsujinaka T, Munakata M, Nishina T, Okamura S, Esaki T, Sasaki Y, Koizumi W, Kakeji Y, Ishizuka N, Hyodo I and Sakata Y: Genotype-directed, dose-finding study of irinotecan in cancer patients with UGT1A1" 28 and/or UGT1A $1^{*} 6$ polymorphisms. Cancer Sci 102: 1868-1873, 2011.

20. Marcuello E, Páez D, Paré L, Salazar J, Sebio A, del Rio E and Baiget M: A genotype-directed phase I-IV dose-finding study of irinotecan in combination with fluorouracil/leucovorin as first-line treatment in advanced colorectal cancer. Br J Cancer 105: 53-57, 2011.

21. Hoskins JM, Goldberg RM, Qu P, Ibrahim JG and McLeod HL: UGT1A1 28 genotype and irinotecan-induced neutropenia: dose matters. J Natl Cancer Inst 99: 1290-1295, 2007.

22. Hu ZY, Yu Q, Pei Q and Guo C: Dose-dependent association between UGT1A1*28 genotype and irinotecan-induced neutropenia: low doses also increase risk. Clin Cancer Res 16: 3832-3842, 2010:

23. Klastersky J, Paesmans M, Rubenstein EB, Boyer M, Elting L, Feld R, Gallagher J, Herrstedt J, Rapoport B, Rolston K and Talcott $\mathrm{J}$ : The multinational association for supportive care in cancer risk index. A multinational scoring system for identifying low-risk febrile neutropenic cancer patients. J Clin Oncol 18: 3038-3051, 2000.

24. Klastersky J, Paesmans M, Georgala A, Muanza F, Plehiers B, Dubreucq L, Lalami Y, Aoun M and Barette M: Outpatient oral antibiotics for febrile neutropenic cancer patients using a score predictive for complications. J Clin Oncol 24: 4129-4134, 2006.

25. Hu ZY, Yu Q and Zhao YS: Dose-dependent association between UGT1A $1 * 28$ polymorphism and irinotecan-induced diarrhoea: a meta-analysis. Eur J Cancer 46: 1856-1865, 2010.

26. Di Martino MT, Arbitrio M, Leone E, Guzzi PH, Rotundo MS, Ciliberto D, Tomaino V, Fabiani F, Talarico D, Sperlongano P, Doldo P, Cannataro M, Caraglia M, Tassone P and Tagliaferri P: Single nucleotide polymorphisms of ABCC5 and ABCG1 transporter genes correlate to irinotecan-associated gastrointestinal toxicity in colorectal cancer patients: a DMET microarray profiling study. Cancer Biol Ther 12: 780-787, 2011.

27. Bleiberg $\mathrm{H}$ and Cvitkovic E: Characterisation and clinical management of CPT-11 (irinotecan)-induced adverse events: the European perspective. Eur J Cancer 32A (Suppl 3): S18-S23, 1996.

28. Merrouche Y, Extra JM, Abigerges D, Bugat R, Catimel G, Suc E, Marty M, Hérait P, Mahjoubi M and Armand JP: High dose-intensity of irinotecan administered every 3 weeks in advanced cancer patients: A feasibility study. J Clin Oncol 15: 1080-1086, 1997.

29. Takeda Y, Kobayashi K, Akiyama Y, Soma T, Handa S, Kudoh S and Kudo K: Prevention of irinotecan (CPT-11)-induced diarrhea by oral alkalization combined with control of defecation in cancer patients. Int J Cancer 92: 269-275, 2001. 